$5-2019$

\title{
The Relationship Between Leadership Style and Personality Type Among College Students
}

Samantha Easley

Dominican University of California

https://doi.org/10.33015/dominican.edu/2019.HONORS.ST.16

Survey: Let us know how this paper benefits you.

\section{Recommended Citation}

Easley, Samantha, "The Relationship Between Leadership Style and Personality Type Among College Students" (2019). Honors Theses. 58.

https://doi.org/10.33015/dominican.edu/2019.HONORS.ST.16

This Honors Thesis is brought to you for free and open access by the Student Scholarship at Dominican Scholar. It has been accepted for inclusion in Honors Theses by an authorized administrator of Dominican Scholar. For more information, please contact

michael.pujals@dominican.edu. 


\title{
The Relationship Between Leadership Style and Personality
}

\section{Type Among College Students}

\begin{abstract}
A successful leader must evaluate the strengths and weaknesses of each team member in order to ensure the most workplace success. Research has shown that an individual's personality type is related to his or her personality style and contributes to how well someone responds to the leadership style. The goal of this study was to look at the personality types of undergraduate college students and assess the relationship to their preferred leadership styles. A positive relationship between both personality traits openness and extraversion with a more transformational leadership style. A positive relationship between both personality traits conscientiousness and neuroticism with a more autocratic leadership style was also expected. The sample included 47 undergraduate students from a small university located in northern California. Participants were recruited in three ways: via email to their supervisors, classroom visits, and requests on personal social media accounts. Participants were asked to complete an online survey that assessed their personality type, preferred leadership style to work with. Results indicated partially confirming the first hypothesis with a positive significant relationship between extraversion and a more transformational leadership style, which means someone who is more social prefers to work with a leader that emphasizes communication. The second hypothesis was partially disproved as there was a negative significant relationship between conscientiousness and a more autocratic leadership style, which means someone who is more organized is less likely to prefer to work with a leader that is very strict.
\end{abstract}

\section{Document Type}

Honors Thesis

Degree Name

Bachelor of Science

Department

Psychology

First Reader

Matt Davis, PhD

Second Reader

William Phillips, PhD

\section{Keywords}

leadership style, personality type, college students, Big 5

\section{Subject Categories}

Business | Educational Leadership | Industrial and Organizational Psychology | Psychology

This honors thesis is available at Dominican Scholar: https://scholar.dominican.edu/honors-theses/58 
Running head: LEADERSHIP AND PERSONALITY

The Relationship Between Leadership Style and Personality Type Among College Students

$$
\text { Samantha Easley }
$$

Submitted in partial fulfillment of the requirements of the Psychology Department and the Honors Program Dominican University of California 2019

First Reader: Matt Davis, Ph. D Department of Psychology

Second Reader: William Phillips, Ph. D Department of Psychology

Honors Director: Lynn Sondag, Ph. D Department of Art \& Art History 


\begin{abstract}
A successful leader must evaluate the strengths and weaknesses of each team member in order to ensure the most workplace success. Research has shown that an individual's personality type is related to his or her personality style and contributes to how well someone responds to the leadership style. The goal of this study was to look at the personality types of undergraduate college students and assess the relationship to their preferred leadership styles. A positive relationship between both personality traits openness and extraversion with a more transformational leadership style. A positive relationship between both personality traits conscientiousness and neuroticism with a more autocratic leadership style was also expected. The sample included 47 undergraduate students from a small university located in northern California. Participants were recruited in three ways: via email to their supervisors, classroom visits, and requests on personal social media accounts. Participants were asked to complete an online survey that assessed their personality type, preferred leadership style to work with. Results indicated partially confirming the first hypothesis with a positive significant relationship between extraversion and a more transformational leadership style, which means someone who is more social prefers to work with a leader that emphasizes communication. The second hypothesis was partially disproved as there was a negative significant relationship between conscientiousness and a more autocratic leadership style, which means someone who is more organized is less likely to prefer to work with a leader that is very strict. Keywords: leadership, personality, college students, the Big 5
\end{abstract}


The Relationship Between Leadership Style and Personality Type Among College Students

\section{Leadership Styles}

Leadership style is prominent in day to day life, regardless of the situation an individual finds him or herself in. Leadership and the need for a leader is as old as the emergence of many civilizations (Landis, Hill, \& Harvey, 2014). Moses, Confucius, Machiavelli, and Plato naturally demonstrated the prominence for constant work toward improvements in leadership ability. Leadership is prominent in maneuvering through life, as people are constantly giving direction and guidance to others. Leadership is defined as "the act of instructing and guiding individuals in a work setting" (Nelson \& Quick, 2015). Though instructing and guiding individuals is not limited to a work setting, the need for this is evident in many aspects of life. Leaders may adopt to various leadership styles due to life experiences and are influenced by the leadership roles that are assumed.

Leadership theories have been evolving over time since the first theories were developed and implemented. A prominent leadership theory recognized today is the Leadership Grid, which was previously referred to as the Managerial Grid. Blake, Mouton, and Bidwell (1962) developed this model to measure leadership based on understanding a leader's perspective on the importance of results and relationships with workers. The Leadership Grid has five main leadership styles, or management styles, that individuals may identify with, which are all determined by the emphasis they place on concern for results. The leaders are asked to rank their concern for people and results on a scale from one to nine, low to high. The first leadership style is "Country Club Management", which describes a leader who identifies with high concern for people and low concern for results. This individual would be someone who is truly empathetic 
and does what it takes to care for the needs of his or her team. These leaders are almost fully focused on the team's satisfaction with the job and overall personal well being. The second leadership style is the "Team Management", which is high on both concern for people and results. This individual encourages the full team to work towards and achieve goals. This leader bases success on trust, respect, and common goals to keep team members motivated and continue working hard. The third leadership style is the "Middle-of-the-Road Management", which is characterized in the middle for both concern for people and results. The focus of this leadership style is to maintain basic levels of productivity within the workplace and a satisfactory level of morale within the team. The fourth leadership style is the "Impoverished Management", which is low on both concern for people and results. This leadership style is only focused on completing the bare minimum and is not focused on team morale. Finally, the fifth leadership style is "Authority-Compliance Management", which is high in concern for results and low concern for people. This leadership style does not allow personal relations within the team to interfere with the production of work. Each worker or follower will respond differently depending upon each leadership style and the situation they are working in.

A leader's characteristics, traits, behaviors, and decisions are open to interpretation by his or her followers (Smith \& Foti, 1998). In a study of 160 male undergraduate students ad a larger university located in the southeastern United States. The students were all enrolled in an Introductory to Psychology course and received extra credit for participating in the study. The participants were divided into groups of four, each including one member that was high in intelligence, dominance, and self-efficacy. Another group member was low in intelligence, dominance, and self-efficacy. Characteristics of the other two were not controlled for. 
It was hypothesized that dominance, intelligence, and general self-efficacy would have a positive relationship with rankings and ratings of leadership. It was also hypothesized that individuals who possessed higher intelligence, dominance, and general self-efficacy would emerge as leaders significantly more often, and vice versa. To measure dominance, the Personality Research Form (Jackson, 1987) a 16 item questionnaire asking participants to rate their argument or disagreement with each various statements regarding dominance. To measure intelligence, the Wonderlic Personnel Test (Wonderlic, 1983) was utilized, which measures how many standard questions an individual answered out of a total of 50 questions. Also, to measure general self-efficacy, the General Self-Efficacy Scale (Sherer et al., 1982) was used. It contains 30 questions that are rated if they strongly disagreed or strongly agreed to determine one's self-efficacy.

The participants had two weeks to complete the questionnaires before being called back to work in their groups of four. Once the questionnaires were completed, the participants were assigned the task of creating various vehicles out of Legos and were asked to sell the product for profit. The session lasted 45 minutes to allow for ample time for the participants to interact with one another. After completing the task, the participants rated their group and themselves on their portrayed leadership ability using the General Leadership Impression (Lord, Foti \& Vader, 1984) in the order that they would prefer to have one member as a leader if they were to have the chance to complete the task again. The relationship between dominance and intelligence showed a statistically significant positive correlation with leadership, meaning having a higher intelligence level relates to being a better leader. General self-efficacy also had a statistically significant positive, correlation with leadership, which means self-efficacy relates to being a 
better leader. The individuals that possess high intelligence, general self-efficacy, and dominance are more likely to emerge as leaders and those who do not possess these traits are less likely to emerge as leaders.

Some individuals can pridefully claim to be "natural born leaders", but there are many individuals that have to work hard on developing the needed skill set. A university setting is an ideal place to foster leadership development, skills, and opportunities (Zorina et al., 2018). Student leadership, for many, is simply part of the college experience. This study was conducted to look for paths to assist students with low leadership qualities to develop their skills and overcome the obstacles they are facing. The authors hypothesized that the participants in this study will identify with new leadership qualities than what has been observed in the past.

\section{Personality Type}

Over time, the theories of personality have evolved and have been interpreted in various ways, depending on which traits are being observed (Revelle, 2009). Personality theories have been and are still being developed to this day, changing as new findings have been discovered. One main contributor to the understanding and development of personality is Cattell. Cattell (1946) began his research with intelligence tests, and he worked to understand the factors that contributed to an individual's overall personal intelligence score. Cattell discussed surface and source traits, which allowed him to understand particular behaviors. For example, feelings of sadness, crying, or depression was considered surface traits that stem from source traits being outgoing, reserved, or happy-go-lucky, which could be measured on emotionality scales. This allowed for further research with personality using traits to describe the reasons behind an individual's behavior. Trait theory can be defined as, "a personality theory that advocates 
breaking down behavior patterns into a series of observable traits in order to understand human behavior" (Nelson \& Quick, 2015). Early personality researchers realized it is important to break down patterns of behavior into traits or characteristics order to better understand the individuals being observed.

The participants in this study included 474 undergraduate students, 297 females and 177 males enrolled at the Elabuga Institute of Kazan Federal University located in Yelabuga, Russia. The participants involved were 246 second-year students and 228 third year students. In 10-15 minutes, the participants were required to look through a list of leadership qualities and alter or add more to the qualities as they saw fit. A second task was given immediately following, asking the participants were offered an additional list containing 25 more leadership qualities. They were given five to seven minutes to complete this task in the same way they worked on the first one. This method, developed by Batarshev (2001), measure the participant's levels of leadership characteristics, communication skills, and organizational qualities.

The main findings of this study were that students that their peers felt comfortable approaching were more likely to get and stay involved leadership roles on campus. The leadership qualities noted were confidence, communication skills, people skills, and openness. For the students who did not identify as a leader, the most prominent reason was their lack of initiative to get involved. Overall, the person-oriented approach to appeal was the most effective outreach method to encourage students to get involved in leadership positions on campus. Some of the most popular personality inventories include the Myers-Briggs Indicator (Myers \& Briggs, 1987) and the NEO Personality Inventory (Costa \& McCrae, 1985), also known as the Big 5. The Myers-Briggs type indicator measures four dichotomies of personality traits. The 
dichotomies include introversion and extraversion, sensation and intuition, thinking and feeling, and judging and perceiving. The NEO Personality Inventory measures the Big 5 personality traits of extraversion, agreeableness, openness, conscientiousness, and neuroticism. These personality inventories break personality types into categories that are representative of different personal characteristics.

Furnham (1996) assessed the relationship between these two inventories and looked at both similarities and differences. The participants in this study consisted of 160 middle to senior managers at a communication organization. There were $91 \%$ males and $9 \%$ females with ages ranging from their late 30 's to their mid 50's. The inventories were distributed to the participants in a management center over a day-long session and were taken via paper and pencil. The Myers-Briggs indicator consisted of a 94 question assessment, and which the questions were all relevant to the participants' preferences that related directly to the four dichotomies. The NEO Personality Inventory is comprised of a questionnaire including 240 statements that participants rated on a 5-point Likert scale noting how relevant each statement of characteristic and description was of their own personality.

After completing the questionnaires, participants were required to meet with a certified manager to go over the results and receive feedback. It was observed that there was a statistically positive correlation between the agreeableness trait from the Big 5 and the Myers-Briggs thinking and feeling dichotomy. There was also a statistically positive correlation between the conscientiousness trait of the Big 5 and the Myers-Briggs thinking and feeling, and to the judging and perceiving dichotomy. As expected, there was also a positive correlation between the extraversion trait and the introversion and extraversion dichotomy. Openness was 
significantly related to all aspects of the Myers-Briggs traits. Finally, the Big 5 trait neuroticism had a negative correlation to the Myers-Briggs trait introversion and extraversion traits and the thinking and feeling traits.

\section{Presence of Leadership and Personality in the Workplace}

In another perspective on leadership styles, Mihalcea (2013) looked at the importance and presence of leadership and personality in the workplace. Mihalcea had one main hypothesis, which was that a good leader has the most power to motivate and continue an effective working team in contrast to a leader who is only focused on the task performance and overall organizational success. Mihalcea had three objectives he wanted to achieve in this study. The first was to identify personality types and leadership styles that generate greater job satisfaction among employees. The second objective was to identify the relationship between transformational and transactional leadership styles and the different personality traits of each type of leader. Transformational leadership is a leadership style in which the leader has the desire and power to create positive change in the team members, while transactional leadership is solely focused on the success of the organization and the employees' performance. The third objective was to determine whether there was a difference between these types of leadership in terms of the overall performance of employees in the workplace.

There were a total of 1272 participants, 521 males, and 751 females in this study and they were retail employees located in Bucharest, Romania. The ages of the participants ranged from 24-51 years. There were 173 participants who held leadership positions within their workplaces. Each employee had worked at least 3 months at their place of employment. Mihalcea controlled for external factors by ensuring a similar environment for the participants. The participants had 
not utilized professional training programs related to leadership in the two years prior to the study taking place. The distributed survey was focused on general demographics, an 87 item questionnaire that measured job satisfaction (Mihalcea, 2013), an evaluation of personality type, and leadership styles.

The results of this study concluded that transformational leadership was not directly related to the satisfaction of employees, but incentives that were the main motivators and resulted in more satisfaction among the employees. When either transformational or transactional leadership was present, it was related to lower employee mistakes and higher department profitability. The study did not show a difference between a more transformational leadership style and overall work satisfaction of employees, which was counter to the hypothesis. It was also found that job satisfaction among the employees was mainly found among transactional leaders that establish clear objectives and give rewards based on performance in a timely manner. The employees worked better in an incentive-based environment.

A majority of the research on leadership style and personality type has been done in a work setting. Another aspect of the study of leadership style is the personality of the followers. Jung (1969) defined personality as characteristics that are derived from an individual's varying attitudes and are developed over time. Understanding an individual's personality allows for insights into why someone acts the way they do (Nicholson, 1998). Personality theories constantly build off of what was discovered previously and have the capability to help us to understand and explain the reasons behind someone's behavior. Allport (1921), one of the first modern trait theorists and a former social worker, had one goal while beginning his work on personality. His goal was to bring "richness and dignity" to the study of personality and human 
nature. His theory divided personality traits into categories: cardinal traits, central traits, and secondary traits. Cardinal traits can be defined as those that have the ability to truly define a person's behavior, view on the world, and emotions. This type of trait is rare and is directly associated with an individual once it has been identified. An example given to describe this trait was Abraham Lincoln's nickname of "Honest Abe". Central traits affect an individual's behavior and are traits that make up one's personality. These traits can include openness, shyness, bravery, and many more. Secondary traits can be described as situational traits, meaning they are not constantly present in one's day to day life, but arise in specific situations. For example, when walking alone at night, one may become anxious though they typically are not like that. The secondary traits are not present constantly but do appear under certain circumstances. Allport's insight and research on personality have allowed for further development of personality traits and characteristics.

Leadership and personality type have been studied in relation to one another many times. The relationship between these variables has proved to produce inconsistent results over time, which has led Hassan, Asad, and Hoshino (2016) to assess this topic. The participants included 35 managers or leaders and 350 subordinates from 35 organizations belonging to software, education, pharmaceutical, banking, and construction industries. Each manager was randomly assigned ten subordinates that were asked to assess his or her leadership style. Questionnaires were electronically distributed to the participants and consisted of 30 statements that were related to the Big Five personality traits, and the leaders were required to provide self-reports of their leadership styles. The leadership questionnaire contained 25 statements that were answered both by the leader, as well as by the subordinates. The leadership qualities included setting clear 
instruction, encouraging participation, goal orientation, professional development, and little concern for managing subordinates' decision making.

It was hypothesized that there would be a strong positive relationship between the leadership characteristics of encouraging participation, goal orientation, and professional development with the Big Five personality traits of openness, agreeableness, extraversion, and conscientiousness. The findings of the showed that the correlation between the dominant leadership styles and these Big Five traits were not statistically significant. The trait that was most important to the participants was conscientiousness as they hoped a good leader would be diligent in their work and pay close attention to details as they work with others.

Leadership qualities and personality traits typically complement each other. Leadership styles are most relevant and evident when working in a team with others to reach a common goal. Taggar, Hackett, and Saha (1999) investigated personality traits and cognitive ability in terms of their effect on leadership emergence. In addition, the researchers investigated the overall impact of a team leader on the other members and team performance. Personality was measured by the NEO Personality Inventory (NEO-PI-R; Costa \& McCrae, 1992) which assess the traits of openness to new experiences, extraversion, agreeableness, conscientiousness, agreeableness, and neuroticism. Cognitive ability was measured by the Wonderlic Personnel Test (Wonderlic, 1983) that is typically used to test the effectiveness of training programs in industrial settings. Finally, leadership was measured by an average of peer assessments. Each individual had to rank the team members on a 5-point Likert scale on whether their peer exemplifies strong leadership and if their peer assumes leadership. 
The participants of this study consisted of 480 undergraduate business students at a medium-sized university, which the location was not included. The participants had an average age of 21 and were $58 \%$ female and $42 \%$ male. The participants were broken into nine groups different groups that were enrolled in a 13-week course. Each course required the participants to get into smaller groups of about five or six. In those small groups, a leader was not assigned to give the participants the opportunity to volunteer as a leader. Overall, 94 groups worked in autonomous teams for 13 weeks and the output from their teams worth $20 \%$ of their overall grade. It was hypothesized that conscientiousness, extraversion, openness, and agreeableness were positively related to each team member's leadership score. Neuroticism was the only trait that was hypothesized to have a negative correlation to leadership scores. It was also hypothesized that there would be a positive correlation between a team member's general cognitive ability and his or her leadership score.

The participants completed each survey over the last three weeks of their class sessions. General cognitive ability and conscientiousness were the most prominent traits of the participants who chose to take on leadership roles within their groups. Extraversion was found to be a prominent antecedent to leadership emergence. Those with extraverted traits were also perceived to be more effective with group outcomes than those with introverted traits. There were no statistically significant findings on the relationship with openness and agreeableness to the team member's leadership score. These traits are most related to effective communication skills, understanding, and empathy which are typically associated with someone is interpreted as a leader. 
Leaders have a large impact on how someone responds to a situation, which also influences one's overall comfort and success within the company or organization. A study conducted by Weed, Mitchell, and Moffitt (1976) had the purpose of determining and understanding the potential relationship between leadership style, the type of task given, and the personality type of the subordinates. The leadership style was based on whether the leaders identified with a high or low task orientation and human relations. Task-oriented leaders focus on completing job duties, while human relations leaders focus on building relationships within the team. The type of tasks given varied on a range from easy to difficult and clear to ambiguous instruction. The personality of the followers could be identified as either slightly or highly dogmatic. There were three hypotheses that were tested in this study. The first was that the task performance would be dependent on all three variables - leadership style, personality type of the followers, and the task type. For example, a leader that was high task-oriented and high human relations-oriented would get the most successful results with a follower who was highly dogmatic and who was given a task that was clear in the instructions and of a higher difficulty level. The second hypothesis was that there was a more successful leadership style that would affect the subordinates based on the task at hand. The researchers expected that highly dogmatic individuals would work best with leaders that were highly task oriented and worse with leaders that were highly human-relations oriented. The third hypothesis was that the subordinates should be more satisfied overall with leaders that were more human-relations oriented than those who were more task-oriented.

The participants in this study included 48 male subjects that were randomly chosen from an introduction to psychology course. There were 24 subjects that scored low on the dogmatism 
scale and 24 that scored high on the dogmatism scale, using the Short-Form Dogmatism Scale (Blumberg, 1972). Each group was broken into pairs with individuals opposite group and randomly assigned to a leader. There were ten leaders, falling into three categories depending on their leadership styles: high task-oriented and high human-relations oriented, high task-oriented and low human-relations oriented, and low task-oriented and high human-relations oriented. The leadership style was determined by the Leadership Grid Questionnaire (Blake, Mouton, \& Bidwell, 1962). The Leadership Grid Questionnaire, which was discussed earlier in this review, is a measure of the task and human relations orientations and asks the participants to rank which orientation they find the most important for a leader. Each group was assigned a task by the leader that varied in ambiguity and difficulty. The subjects were given the task at the beginning of the session and had 15 minutes to complete it.

The researchers measured performance by observing the responses and the subjects' completed satisfaction questionnaire. The subjects were asked to rate their overall experience with their leader, the potential of the leader, and to what extent the leader was able to motivate them - all on five-point scales. There was one statistically significant finding regarding the importance of leadership style and personality type when the task was both difficult and ambiguous. It was concluded that the high task-oriented and high human relation-oriented leadership style produced the best results when the task was difficult and ambiguous. There were no statistically significant findings for the last two hypotheses, though in general, it was found that leaders high on both human-relations and task-oriented leadership did better with low dogmatism subjects. The limitations of the study included the short time frame (under 1.5 hours) of the experiment and there was only a small number of situations for the participants to assess 
the leadership style. The relationships that leaders have with their followers played a large role in the success of the organization.

It is natural for individuals to look to their leaders as an example of how to behave in various situations, which allows the leaders to set the stage on how the people around them will act. Cavazotte, Hickman, and Moreno (2015) observed the effect a leader's personality and emotional intelligence on transformational leadership and the overall managerial performance. The leader's effectiveness was measured by the ability to and success at fulfilling the organizational goals. Transformational leaders are leaders that are individuals with the power to implement social and organizational change (Bass, 1985). The Multifactor Leadership Questionnaire was used to measure the individual's transformational leadership style (Bass \& Avolio,1997). This scale uses a 5-point Likert scale to rate five components of leadership styles which include idealized influence on attributes, idealized influence on behavior, motivational inspiration, intellectual stimulation, and individual consideration. The leadership qualities are mainly focused on the leader fostering growth within their team's performance and personal qualities. The personality of the leaders was measured using the Five Factor Model, or Big 5 (Costa \& McCrae, 1992) an extraversion, agreeableness, conscientiousness, openness, and neuroticism measure.

The participants in this study included mid-level managers from a large Brazilian company. The sample included 134 managers with 85 men and 49 women ranging in age from 29 to 73 years old. The participants were all in managerial positions for an average of nine years. To evaluate the managerial performance on the leaders, there were 325 subordinates anonymously answering questions, following the measurement scales, on their leaders. The only 
additional information that was required on the survey indicates whether the participant was a subordinate or leader. It was hypothesized that there was going to be a positive relationship between transformational and extraversion, openness, and conscientiousness. It was also hypothesized that there was going to be a negative relationship between transformational leadership and neuroticism.

Transformational leadership and overall managerial performance were shown to be affected by each trait. Conscientiousness had an apparent relationship to transformational leadership, but indirectly affected the effectiveness of the manager's leadership. Neuroticism held true to the hypothesis and had a negative correlation to the leader's perceived effectiveness. The results for the remaining hypotheses were not statistically significant.

Institutions of higher education are a common place to find many leaders within one population. This environment allows for individuals to grow based on their personality types, which leads to leadership development as well (Samardžja, Walker, \& Kužnin, 2017). These researchers conducted a study to observe and record the most prevalent leadership qualities and behaviors across the student body population in relation to their family backgrounds. The authors hypothesized that there was not going to be a statistically significant finding between leadership and the number of siblings and the size of the city which the participant grew up. The participants of the study included 127 students, 62 male, and 64 female from a Croatian university campus. The questionnaire was designed to include questions from the Big Five personality assessment and to address the individual's perspective on leadership qualities.

The hypotheses were upheld, which meant that there was no significant relationship between leadership style and the way that the participants' family background. Although, 
leadership styles did have a positive significant difference between participants who moved around growing up versus participants who stayed in one residence. Overall, participants were able to define what leadership qualities they found most important. The participants agreed that successfulness was a determining factor of leadership. They also noted that individuals loving their work while satisfying their personal needs was also appreciated in a leader.

Adams (2009) looked at the extent of the relationship, if any, between personality type and general leadership style. Adams wanted to determine if there was any between the personality traits of extraversion versus introversion, sensing versus intuition, feeling versus thinking, and judging versus perceiving and leadership style (Myers \& Briggs, 1987). The researcher tested three hypotheses in this study: first, that there would be a stronger positive relationship between the collaborative leadership approach and intuition. A collaborative leadership approach ensures the participation of everyone who is part of the team. Second, Adams hypothesized a strong positive correlation between the collaborative leadership approach and the perceptive personality type. Finally, it was expected that there would be a strong negative relationship between leadership style and the judging versus perceiving and extraversion versus introversion traits.

The participants in this study included school administrators, comprised of middle and high school principals and assistant principals in one school district. The administrators were comprised of ten females and four males. The participants were given a paper and pencil questionnaire to measure basic demographic information, employment history, the Keirsey Temperament Sorter (Keirsey \& Bates, 1984), and the Leadership Beliefs Inventory (Glickman, 2002), which measures leadership style. The questionnaires were self-administered. The 
Instructional Leadership Belief Inventory was divided into two sections. The first part of the inventory was focused on the leadership style that participants' preferred working under. The second part looked at the leadership style that the participant used when forced to make decisions.

This survey asked the administrators to list the leadership approach they used most and how often they used it. The leadership approaches included directive-informational, collaborative, or nondirective styles. A leader demonstrating a directive leadership approach sets clearly defined objectives and instructions for the team members, emphasizing clarity. A leader demonstrating a collaborative leadership style focuses mainly on building the team dynamic and personal relationships with each member of the team, so it is easier to all make decisions about the organization. A leader demonstrating a nondirective leadership approach emphasizes the importance of the team sharing ideas and thoughts on the organization to consider everyone's' perspective.

Results demonstrated that none of the participants listed that they used one leadership style $100 \%$ of the time. As predicted, the preferred leadership style was collaborative, with half of the participants reporting they prefer that style. The most preferred leadership style used in a forced decision-making situation was nondirective. The results were contrary to the researchers' hypotheses. Unfortunately, the sample was small and did not draw from a widely diverse group of individuals. The participants were all employed in the same school district and were comprised of mainly female participants. Individuals may respond to different leadership styles due to how each style caters to the individual's needs. 


\section{The Present Study}

The present study focused on aspects of an individual's personality are related to particular leadership styles. While it has been demonstrated in previous research that it is likely for the personality trait of extraversion to be positively related to a more transformational leadership style, there is not a lot of research on other personality traits in relation to preferred leadership styles. The goal of the present study is to gain a better understanding of which types of people are going to benefit more and prefer to work under various leadership styles. It was expected that there would be a strong positive relationship between participants scores on the traits of openness and extraversion and a more transformational leadership style. It was also expected that there would be a strong positive relationship between participants scores on the traits of conscientiousness and neuroticism and a more autocratic leadership style.

\section{Method}

\section{Participants}

The participants in this study consisted of undergraduate students from a small, private liberal arts university located in northern California. The participants were recruited through convenience sampling. The participants were recruited via email, in class requests, and on social media. Supervisors of leadership groups on campus were contacted via email requesting participation in this study. After requesting approval to present the study in a class visit, the link for the survey was distributed to all class members to complete the survey at their will. Requests for participants were also posted on various social media platforms. The only requirement to be eligible to participate in this study was that the participant had to be a current undergraduate student at the university where this study took place. 
A total of 47 participants volunteered for the study, consisting of $17 \%$ male and $83 \%$ female participants. Participants ages ranged from 18-23 years old and averaged at 20.4 years old with a standard deviation of 1.21 . The participants identified as $28 \%$ Hispanic/Latino, $36 \%$ White or Caucasian, 12\% Black or African American, 21\% Asian or Pacific Islander, and 2\% mixed ethnicities. Figure 1 demonstrates the breakdown of ethnicities. The participants included $13 \%$ freshman students, $18 \%$ sophomore students, $29 \%$ junior students, and $40 \%$ senior students. Figure 2 demonstrates the breakdown of the participants' class standing.

\section{Materials}

The survey for this study included four components that the participants needed finish in order for the survey to be considered complete. The participant was first presented with a letter of introduction in which indicates that this study is asking for voluntary participation and the general topic of the survey. The participants were told the purpose of the study before taking the survey. The participants were ensured that their responses were completely voluntary, anonymous, and had the opportunity to withdraw from the study at any time. The survey distributed to participants, see Appendix A, had three sections: demographic questions, a leadership scale, and a personality scale.

Demographics. The participants were asked to complete a short set of demographic questions. The first questions asked for background information of the participant such as gender, age, and ethnicity. The last three questions were about one's educational background and campus involvement in extracurricular activities with questions regarding class standing, their field of study, and whether the participant was involved in any student leader position. 
The Akron Leadership Scale. The Akron Leadership Questionnaire (Lord, Foti, \& De Vader, 1984) was utilized to better understand the participants' view on the characteristics of an ideal leader. The participant was instructed to rate how they felt about each of the statements This scale is comprised of 25 statements that are rated on 5 point scales ranging from 1 (not well at all) to 5 (extremely well) and included characteristics such as "seeks information", “emphasizes feelings", "makes jokes", and more. The participants responded to statements regarding how each statement fit their image of a leader.

The Big Five Personality Scale. The Big Five Personality Questionnaire (Marizot, 2014) was utilized to gather information on an individual's personality type. The scale is comprised of 50 statements that are rated on 5 point scales with 1 indicating "totally disagree" and 5 indicating "totally agree". Respondents were asked to rate how well each of the statements described them. The statements included phrases such as "likes to reflect", "tries to understand complex things", "likes to cooperate with others", "can do things impulsively without thinking about the consequences". This survey is designed to measure five main character traits of an individual which include extraversion, openness, agreeableness, emotional stability or neuroticism, and conscientiousness.

\section{Procedure}

Participation in the survey was recruited in person and via social media platforms such as Facebook, Instagram, and Twitter with a brief post and attached link. Participants were told that the study was designed to examine the relationship between an individual's personality type and leadership style. Participants interested in being in the study followed a link to an online survey supported on surveymonkey.com. Prior to completing the survey, the participants read the letter 
of introduction noting that the survey is completely voluntary and anonymous, the participant has the right to withdraw from the study at any moment, and where to find the results once the study has been completed. To complete the survey, the participants responded to general demographic questions, the Akron Leadership Questionnaire, and the Big Five Personality Questionnaire. The survey was administered on Survey Monkey and was submitted through the online platform and took roughly eight minutes to complete. The participants were then thanked and reminded how to obtain the results of the study.

\section{Results}

There were $82 \%$ of participants that noted that they were part of on-campus leadership groups. These groups include the student body government (ASDU), Resident Advisors, Student Ambassador Team, club leaders, student-athletes, and Orientation Leader Team.

The first hypothesis was that the personality traits of openness and extraversion as measured on the Big Five Personality Test (Marizot, 2014) would be positively correlated with a more transformational leadership style. The first hypothesis was formulated because an individual who identifies more with the personality trait of openness is are more creative and open-minded, while those who identify with the personality trait of extraversion are more social and outgoing. It was expected that those individuals would prefer to work with a more transformational leader because the leader would allow for the subordinates to work closely with team members, gathering input from one another, and collaborating to make decisions. The second hypothesis was that the personality traits of conscientiousness and neuroticism would be positively correlated to a more autocratic leadership style. The second hypothesis was formulated because an individual who identifies with a more conscientious personality trait is more likely to 
be very organized and systematic, while those who identify with a more neurotic personality trait are more anxious. It was expected that those individuals would prefer to work with a more autocratic leader because the leader would make the decisions and the subordinates would only have to follow the given instructions in order to complete the task.

To test these hypotheses, a series of Pearson correlations were conducted between the subscales of the Big 5 and subscales of the Akron Leadership Measure. For both scales, higher scores indicate agreeing with and relating to the statement on the survey. The results demonstrated a significant relationship among six of the 30 pairs of the personality traits and leadership styles. Results of these analyses are located in the Correlation Matrix in Table 1.

As demonstrated in Table 1, there was a positive significant relationship between the extraversion personality trait and the transformational leadership style $(r(45)=+.407, p<.01)$, see Figure 3. As hypothesized, there was a significant positive correlation between the extraversion personality trait and a more transformational leadership style, meaning those who are more social and people-oriented tend to prefer to work with a leader that emphasizes effective communication and group work. However, contrary to the first hypothesis, there was no significant relationship between openness and a more transformational leadership style.

Also demonstrated in Table 1, there was a negative significant relationship between the conscientiousness personality trait and a more autocratic leadership style $(r(45)=-.406, p<.01)$, see Figure 4. Contrary to the second hypothesis, there was a significant negative relationship between the conscientiousness personality trait and a more autocratic leadership style, meaning those who are more organized and systematic tend to be less likely to prefer to work with a 
leader that makes the decisions for the team. Additionally, the remaining statistically significant findings can be found in Table 1.

To consolidate the leader characteristics from the Akron Leadership Questionnaire (Lord, Foti, \& De Vader, 1984), a factor analysis was conducted. The Kaiser-Meyer-Olkin (KMO) measure of sampling adequacy demonstrated the strength among the variables was moderately strong $(\mathrm{KMO}=.64)$ and six factors were determined. Meaning, the factor determined which variables are related to one another in order to categorize them into leadership styles. For the pattern matrix, see Figure 2. The categories of leadership styles were determined according to the characteristics in each group. The 25 statements of leadership characteristics were consolidated into six leadership styles.

\section{Discussion}

The purpose of this study was to gain insight into the preferred leadership style among college students based on their personality traits. It was hypothesized that individuals who possess stronger aspects of the personality traits of openness and extraversion would prefer a more transformational leadership style to work under. It was also hypothesized that individuals who identified more with the personality traits of conscientiousness and neuroticism would prefer a more autocratic leadership style to work under.

The first hypothesis was partially confirmed as there was a statistically significant positive relationship between extraversion and preference for working under a transformational leadership style. However, no statistically significant relationship between openness and preference for the transformational leadership style. This means that those who prefer to work 
under a transformational leadership style were more likely to be extraverted, though there was no particular relationship with openness.

The second hypothesis was also partially disproved as there was a statistically significant negative relationship between conscientiousness and a preference for the autocratic leadership style and no statistically significant relationship between neuroticism and desire to work under an autocratic leadership style. This means that those who prefer to work under an autocratic leadership style are less likely to possess the personality trait of conscientiousness, though there was no particular relationship with neuroticism. The relationship between the transformational leadership style and the extraversion personality trait was expected and is constant with previous research. Cavazotte, Hickman, and Moreno (2015) found that the personality traits openness, conscientiousness, and extraversion were positively related to the transformational leadership style, therefore the present study supports previous research.

There were various limitations of this study to be considered while interpreting the results that have been presented. The sample size was small, with 47 participants. In addition, there was an unequal gender ratio in the sample that included only $17 \%$ male and $83 \%$ female participants in the study, which makes the generalizability of the study less reliable and may have contributed to the failure to confirm some of the hypotheses. A majority of participants were recruited via social media which could have led to bias due to the personal relationships with the researcher. This may have created bias as being friends of the researcher, the participants may be aware of the researcher's ideal results of the study, so they may answer the survey questions according to how they think the researcher wants it to turn out. 
The main limitation that may have affected the results of this study was the use of the Akron Leadership Questionnaire. While the measure did allow for the participant to indicate which characteristics of a leader they preferred to work with, it did not indicate which leadership styles these characteristics corresponded with. A factor analysis needed to be conducted to group items from the questionnaire into a number of discrete leadership styles. This is a major limitation as there was room for personal error and general subjectivity when determining which leadership styles.

A recommendation for future research on this topic is to use a leadership measure that has predetermined subscales for identifying various leadership styles. This might decrease the subjectivity of the present study when determining the leadership styles that the participants indicate they prefer.

In addition to the measure, a larger sample size would make future research more generalizable. Potentially surveying undergraduate students from more diverse universities, from small private schools to large public schools will make for a more diverse sample. This will allow for a better understanding of college students in general, rather than a limited population such as the one in the present study.

A final recommendation for future research would be to conduct an experiment with participants working directly under a supervisor portraying each observed leadership style and have the participants rank which leader they prefer to work with. The participants could take a personality inventory to determine which personality traits are most prominent for each of them, and these results could be analyzed to determine whether individuals with certain personality characteristics prefer particular leadership styles. 
In general, further research on the relationship between personality trait and leadership styles among college students will be beneficial as it is a lesser researched topic. College students may provide different findings from working-age individuals, as the college students are still developing into adults. They may also provide different results because they do not have as much exposure to multiple supervisors and leaders, unlike someone who has been in the workforce for over ten years. College students are constantly working in groups that have a leader, whether it is in their workplace, during group projects, or in extracurriculars, and are also being taught how to be leaders themselves during their education. Having an understanding of why particular people have preferences for the leaders they encounter is beneficial to many in both the leadership and subordinate positions. It is beneficial to the subordinate as they are working to develop their leadership style through the supervisors they encounter. From the leader's perspective, having an understanding of one's own leadership style in relation to their subordinates' personality traits and preferred work styles is important as this knowledge can increase productivity if everyone's needs are being met and addressed.

Knowing which leadership style is most beneficial to a person with particular personality traits can produce optimal results in a workplace. Also having an understanding of which traits do not work well with a particular leadership style can benefit the leader as they might then be able to shift their leadership style to accommodate workers with different needs. Ultimately, knowing oneself as a leader and as a subordinate is as important as having an understanding of the personality traits and preferences of everyone on the same team. 


\section{References}

Adams, D. L. (2009). Personality and leadership approach. Journal of Leadership Education, 8 (2), 111-134.

Allport, G. (1921). "Personality and Character," Psychological Bulletin 18: 441-455.

Bass, B. M. (1985). Leadership and performance beyond expectations. New York: Free Press.

Bass, B. M., \& Avolio, B. J. (1997). Full range leadership development: Manual for the multifactor leadership questionnaire. Palo Alto, CA: Mindgarden.

Batarshev, A. V. (2001). Psychodiagnostics of Abilities to Communicate or How to Identify Organizational and Communicative Qualities of a Person. Moscow, VLADOS, pp. 176.

Blake, R. R., Mouton, J. S., \& Bidwell, A. C. (1962). Managerial grid. Advanced Management Office Executive, 1(9), 12-15.

Blumberg, R. W. (1972). Therapist leadership and client dogmatism in a therapy analogue. Psychotherapy: Theory, Research \& Practice, 9(2), 132-134.

Briggs, K. \& Meyers, I. (1987). Myers-Briggs Type Indicator Form G. Palo Alto, CA: Consulting Psychologist Press.

Cattell, R. B. (1946). Personality structure and measurement. II. The determination and utility of trait modality. British Journal of Psychology, 36, 159-174.

Cavazotte, F., Hickmann, M., \& Moreno, V. (2015). Effects of leader intelligence, personality and emotional intelligence on transformational leadership and managerial performance. The Leadership Quarterly, 23, 443-445.

Costa, P. T., Jr., \& McCrae, R. R. (1992). NEO PI-R. The Revised NEO Personality Inventory. Odessa, FL: Psychological Assessment Resources. 
Costa, P. T., Jr., \& McCrae, R. R. (1985). Reinterpreting the Myers-Briggs from the perspective of the Five Factor Model of personality. Journal of Personality, 11, 17-40.

Furnham, A. (1996). The Big Five versus the Big Four: the relationship between the Myers-Briggs Type Indicator (MBTI) and NEO-PI five factor model of personality. Personality and Individual Difference, 21(2), 303-307.

Glickman, C. D. (2002). Leadership for learning: How to help teachers succeed. VA: Association for Supervision and Curriculum Development.

Hassan, H. Asad, S., \& Hoshino, Y. (2016). Determinants of Leadership Style in Big Five Personality Dimensions. Universal Journal of Management, 4(4), 161-179.

Jackson, D. N. (1987). Personality Research Form Manual. Goshen. NY: Research Psychologists Press.

Jung, C. G. (1969). The structure of the psyche. In Read, H., Fordham, M., Adler, G., \& McGuire, W. (Eds.) (R. F. C. Hull, Trans.), The collected works of C. G. Jung: Vol. 8. The structure and dynamics of the psyche (2nd ed., pp. 139-158). Princeton, NJ:

Princeton University Press. (Original work published 1931)

Keirsey, D., \& Bates, M. (1984). Please understand me: character and temperament types. Del Mar: Prometheus Nemesis Book.

Landis, E., Hill, D., \& Harvey, M. (2015). A Synthesis of Leadership Theories and Styles. Journal of Management Policy and Practice, 15(2).

Lord, R. G., Foti, R. J., \& De Vader, C. L. (1984). A test of leadership categorization theory: Internal structure, information processing, and leadership perceptions. Organizational Behavior and Human Performance, 34, 343-378. 
Lord, Robert G., Foti, Roseanne J., \& De Vader, C. L. (1984). Akron Leadership Questionnaire [Database record]. Retrieved from PsycTESTS.

Mihalcea, A. (2013) Leadership, personality, job satisfaction, and job performance. Procedia-Social and Behavioral Sciences, 127 (2014), 443-447.

Mihalcea, A. (2013). The Impact of Leader's Personality on Employees' Job Satisfaction. Procedia-Social and Behavioral Sciences, 78, 90-94.

Morizot, J. (2014). Big Five Personality Trait Short Questionnaire [Database record]. Retrieved from PsycTESTS.

Nelson, D. L., \& Quick, J. N. (2015). ORGB 4: Organizational Behavior. Stamford, CT: Cengage Learning.

Nicholson, I. A. (1998) Gordon Allport, character, and the "culture of personality," 1897 - 1937. History of Psychology, 1 (1), 52-68.

Revelle, W. (2009). Personality structure and measurement: the contributions of Raymond Cattell. British Journal of Psychology, 100, 253-257.

Samardžja, J., Walker, J., \& Kužhin, M. (2017). Student Leadership, Career Development, Personal Success Profiles. International Journal of Instruction, 9(2).

Smith, J., \& Foti, R. (1998) A Pattern Approach to the Study of Leader Emergence. Leadership Quarterly 9(2). 147-160.

Sherer. M.. Maddux, J. E., Mercadante, B., Prentice-Dunn. S., Jacobs, B., \& Rogers. R. W. (1982). The self-efficacy scale: Construction and validation. Psychological Reports, 51, 663-671. 
Taggar, S., Hackett, R., \& Saha, S. (1999). Leadership Emergence in Autonomous Work Teams: Antecedents and Outcomes. Personnel Psychology, 52, 899-926.

Weed, S. E., Mitchell, T. R., \& Moffitt, W. (1976). Leadership style, subordinate personality, and task type as predictors of performance and satisfaction with supervision. Journal of Applied Psychology, 61(1), 58-66.

Wonderlic, E.L, \& Associates (1983). Wonderlic Personnel Test and scholastic level eram. Libertyville, IL: Wonderlic Personnel 'Rst, Inc.

Zorina, A., Yarullina, A., Akhemetova, L., Shaimardanova, M., Nikishina, S., \& Garipova, A. (2018). Leadership in the University Student Environment: How to Become a Person-Oriented Leader. International Journal of Instruction, 11(4), 271-286. 


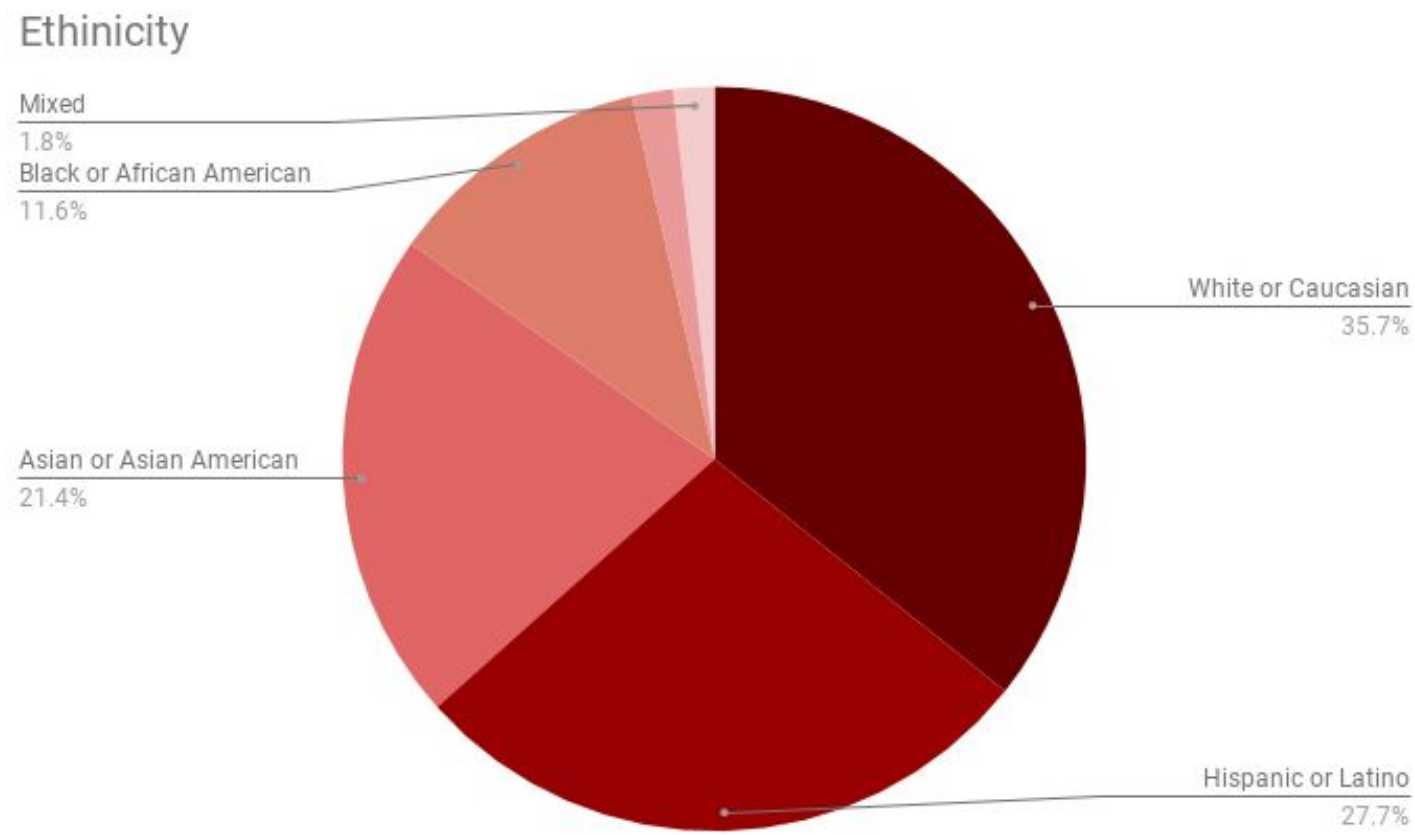

Figure 1.

Ethnicity Breakdown $(\mathrm{n}=47)$

\section{Class Standing}

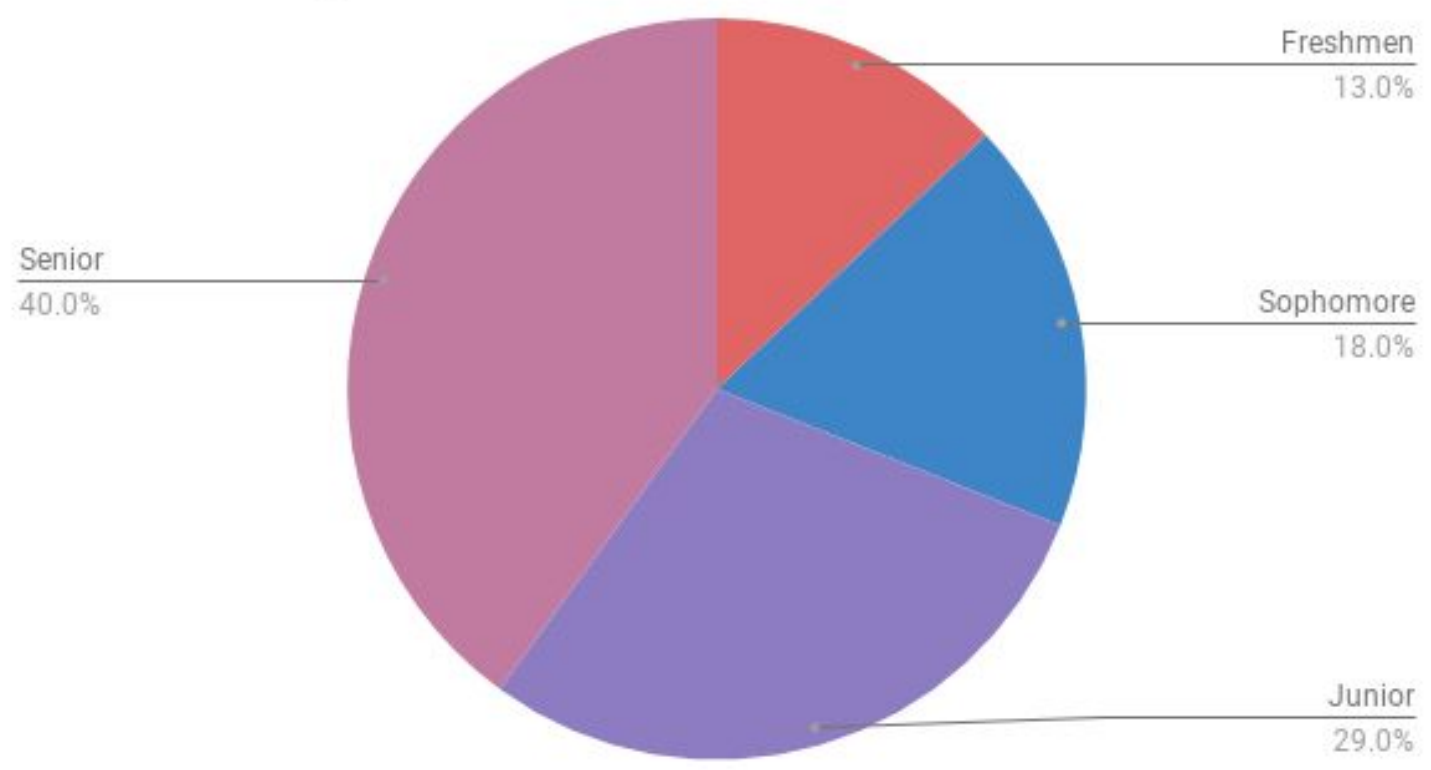

Figure 2.

Class Standing Breakdown $(\mathrm{n}=47)$ 


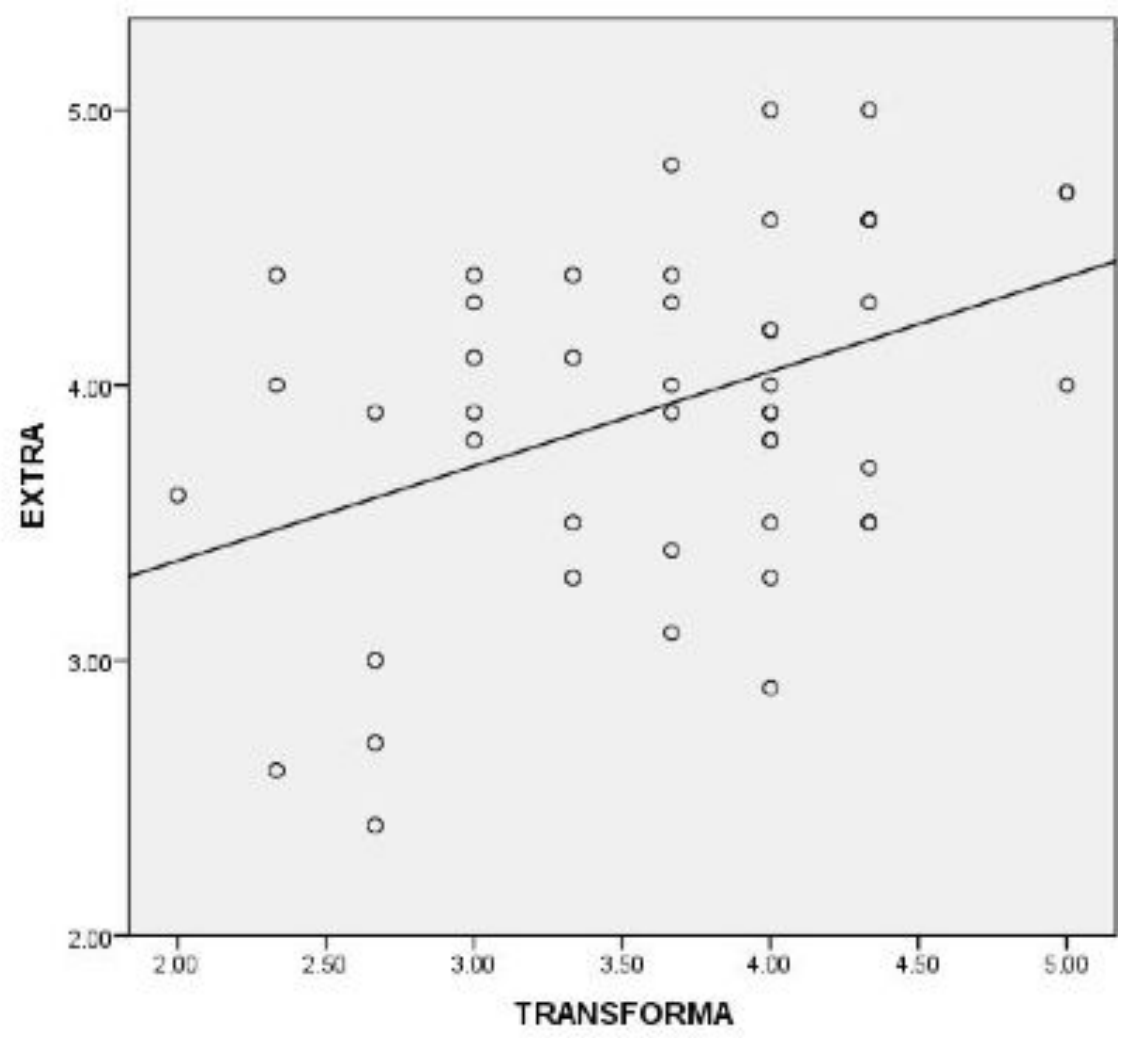

Figure 3.

Relationship Between Extraversion and Transformational Leadership Style 


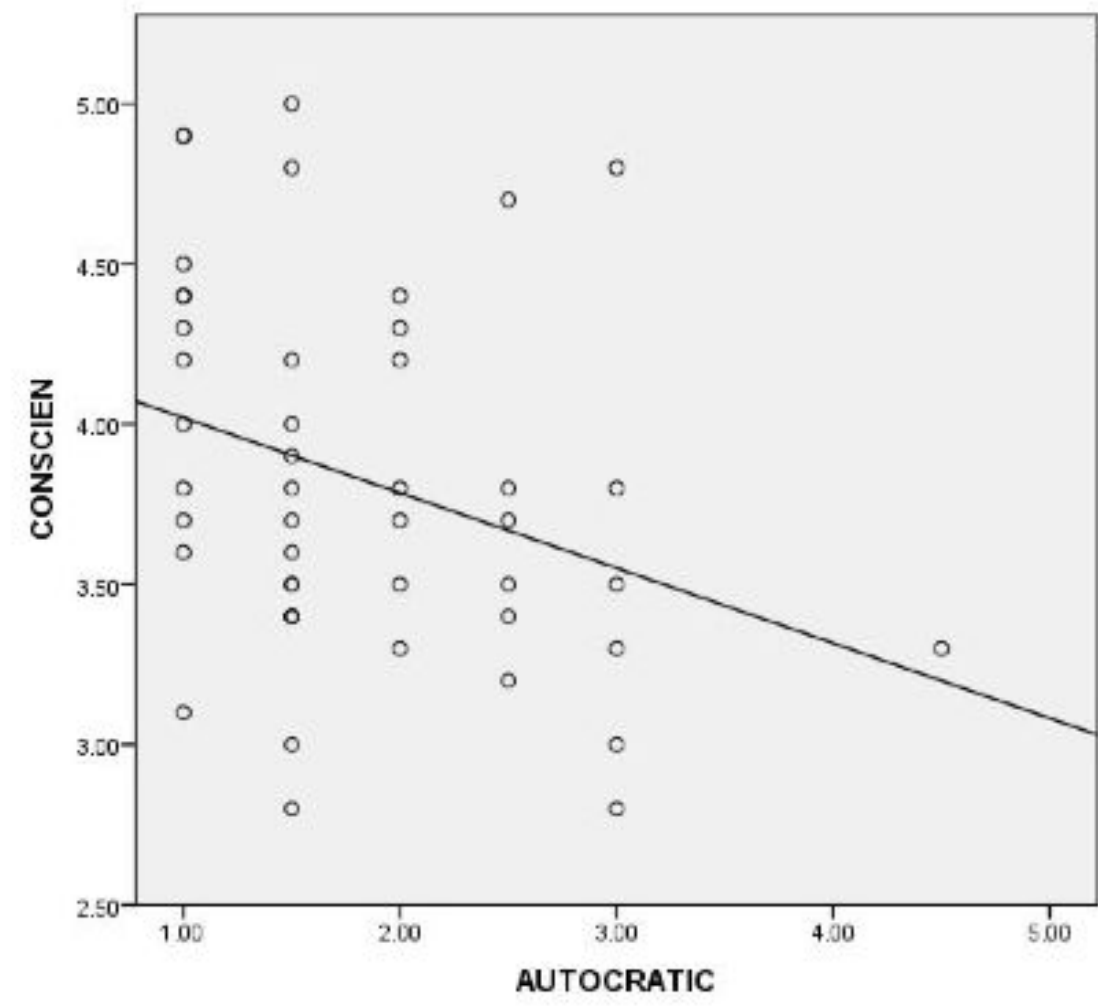

Figure 4.

Relationship Between Conscientiousness and Autocratic Leadership Style 
Table 1.

Correlation Matrix for Leadership Style and Personality Variables $(n=47)$

\section{Leadership Styles}

\section{Big 5}

Personality Democratic Servant Transformational Transactional Laissez- Autocratic Traits Faire

\begin{tabular}{lcccccc}
\hline Openness & .054 & -.003 & .178 & .128 & .193 & -.016 \\
Extraversion & .204 & .123 & $.407 * *$ & -.025 & .096 & -.006 \\
Agreeable. & -.146 & $.412^{* *}$ & $-.397^{* *}$ & .235 & $.404 * *$ & $-.406^{* *}$ \\
Conscient. & .270 & -.101 & .102 & .151 & -.074 & $-.317^{*}$ \\
Neuroticism & .209 & -.097 & .118 & -.203 & .108 & -.210 \\
\hline
\end{tabular}

**. Correlation is significant at the 0.01 level (2-tailed)

*. Correlation is significant at the 0.05 level (2-tailed) 
Table 2.

Pattern Matrix for Leadership Characteristics

Scale Items

\section{Factor}

3

4

5
Emphasizes goals

Emphasizes deadlines

Allocates decisions

Seeks information

Provides information

Explains actions

Proposes solutions

Specifies problems

Exercises influence

Coordinates groups

Makes suggestions

Argues convincingly

Integrates information

Seeks suggestions

Admits mistakes

Withholds rewards

Clarifies attitudes

Talks frequently

Agrees readily

Emphasizes feelings

Prevents conflicts

Requests approval

Makes jokes
.834

.808

.747

.747

.644

.602

.590

.589

.554

Neglects details

.514

.816

.754

.582

Criticizes harshly

.790

.764

$-.648$

.610

Extraction method Principal Component Analysis

* 6 components extracted 


\section{DEMOGRAPHIC QUESTIONS}

\section{APPENDIX A}

Thesis Survey

1. What is your sex?

Female:

Male:

Other (please specify):

2. Please specify your ethnicity (please check all that apply):

White or Caucasian:

Hispanic or Latino:

Black or African American:

Native American or American Indian:

Asian / Pacific Islander:

Other (please specify):

3. Please indicate your current class standing:

Freshman

Sophomore

Junior

Senior

4. Please list your major(s) and minor(s), (if applicable):

Major:

Minor:

5. Are you involved in any role(s) as a student leader?

Yes:

No:

If yes, please specify:

\section{AKRON LEADERSHIP QUESTIONNAIRE}

For each of the following items, please rate how well or how poorly the item fits your image of a leader.

a. Explains actions

not well at all somewhat well moderately well very well extremely well 


\section{b. Seeks information}

not well at all somewhat well moderately well very well extremely well

1

3

45

c. Agrees readily

not well at all somewhat well moderately well

12

3

4

5

\section{d. Makes suggestions}

not well at all somewhat well moderately well very well extremely well

$1 \quad 2$

34

5

e. Criticizes harshly

not well at all somewhat well moderately well very well extremely well

123

34

5

\section{f. Prevents conflicts}

moderately well

very well

extremely well

$$
1
$$

$$
2
$$

3

4

5

\section{g. Emphasizes deadlines}

not well at all somewhat well

$$
12
$$

\section{h. Specifies problems}

not well at all somewhat well

$$
12
$$

\section{i. Coordinates groups}

not well at all somewhat well

12

\section{j. Neglects details}

not well at all somewhat well

12

\section{k. Proposes solutions}

not well at all somewhat well

12

\section{l. Emphasizes feelings}

not well at all somewhat well

1

2 moderately well

3

moderately well

3

moderately well

3

moderately well

3

moderately well

3

moderately well very well

3 very well

4

very well

4

very well

4

extremely well

5

extremely well

5

extremely well

5

very well extremely well

45

5

extremely well

5

extremely well 
m. Makes jokes

not well at all

1

2

very well

extremely well

\section{n. Seeks suggestions}

not well at all somewhat well

1

2

\section{o. Argues convincingly}

not well at all somewhat well

1

2

\section{p. Provides information}

not well at all somewhat well

12

2

\section{q. Requests approval}

not well at all somewhat well

12

2

\section{r. Admits mistakes}

not well at all somewhat well

12

s. Clarifies attitudes

not well at all somewhat well

12

t. Withholds rewards

not well at all somewhat well

12

2

u. Exercises influence

not well at all somewhat well

12

\section{v. Emphasizes goals}

not well at all somewhat well

12

\section{w. Talks frequently}

not well at all somewhat well

1

2 moderately well

3

moderately well

3

moderately well

3

moderately well

3

very well

4

$$
4
$$

extremely well

5

very well

4

very well

4

extremely well

5

extremely well

5

moderately well

3

very well

4

extremely well

5

moderately well

3

very well

4

extremely well

5

moderately well

3

very well

4

extremely well

5

moderately well

3

very well

4

extremely well

5

moderately well

3

very well

4

extremely well

5

moderately well

3 very well

4 extremely well 
$x$. Integrates information

not well at all somewhat well moderately well very well extremely well

$\begin{array}{lllll}1 & 2 & 3 & 5\end{array}$

\section{y. Allocates decisions}

not well at all somewhat well moderately well very well extremely well

$\begin{array}{lllll}1 & 2 & 3 & 5\end{array}$

\section{BIG 5 PERSONALITY QUESTIONNAIRE}

For each of the following items, please indicate how much you agree or disagree with how the statement describes $\underline{\text { YOU}}$.

Is original, often has new ideas

totally disagree disagree a little neutral agree a little totally agree

$\begin{array}{lllll}0 & 1 & 2 & 3 & 4\end{array}$

Likes to talk, expresses their opinion

totally disagree disagree a little

neutral agree a little totally agree

$0 \quad 1$

23

4

Has a tendency to criticize others

$\begin{array}{ccccc}\text { totally disagree } & \text { disagree a little } & \text { neutral } & \text { agree a little } & \text { totally agree } \\ 0 & 1 & 2 & 3 & 4\end{array}$

Works conscientiously, does the things he/she has to do well

totally disagree disagree a little neutral agree a little totally agree

0

23

4

Has a tendency to be easily depressed, sad

totally disagree disagree a little neutral agree a little totally agree

$\begin{array}{lllll}0 & 1 & 2 & 3 & 4\end{array}$

Is curious about many different things

totally disagree disagree a little neutral agree a little totally agree

$\begin{array}{lllll}0 & 1 & 2 & 3 & 4\end{array}$

Is reserved or shy, has difficulty approaching others

totally disagree disagree a little neutral

totally agree 
Is helpful and generous with others

totally disagree disagree a little

neutral

2

0
1

agree a little

3

totally agree

4

Can be a little careless and negligent

totally disagree

disagree a little

1

0

neutral

2

agree a little

3

totally agree

4

Is generally relaxed, handles stress well

totally disagree

disagree a little

neutral

2

agree a little

3

totally agree

$$
0
$$

1

Is ingenious, reflects a lot

totally disagree

disagree a little

1

neutral

2

agree a little

3

totally agree

0

Is full of energy, likes to always be active

totally disagree

disagree a little

neutral

2

agree a little

3

totally agree

$$
0
$$

1

2

Provokes quarrels or arguments with others

totally disagree

0 disagree a little

1 neutral

2 agree a little

3 totally agree

4

Is a reliable student/worker, who can be counted on

totally disagree

disagree a little

neutral

2

0

1

Can be tense, stressed out

totally disagree

disagree a little

1 neutral

2 agree a little

3

agree a little

3 totally agree

4

totally agree

4

4

Has a lot of imagination

totally disagree

0 disagree a little

1 neutral

2 agree a little

3 totally agree 
Is a leader, capable of convincing others

totally disagree

0

disagree a little

1 neutral

2

\section{Is lenient, forgives easily}

totally disagree

disagree a little

0

1

Has a tendency to be disorganized, messy

totally disagree

disagree a little

0

1

Worries a lot about many things

totally disagree

disagree a little

0

1

Is inventive, creative

totally disagree

disagree a little

0

1

neutral

2

2

Is rather quiet, does not talk a lot

totally disagree

disagree a little

neutral

2

0

1

Generally trusts others

totally disagree

disagree a little

0

1

Has a tendency to be lazy

totally disagree

disagree a little

0

1

Is emotionally stable, not easily upset

totally disagree

disagree a little

0 neutral

2

neutral

2

neutral

2 agree a little

3

agree a little

3

agree a little

3

totally agree

3

4

agree a little

3

totally agree

4

4

4

totally agree

4

totally agree

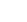

totally agree

4

3

agree a little

totally agree

3

4

totally agree

4 
Likes artistic or aesthetic experiences

totally disagree

0 disagree a little

1 neutral

2 agree a little 3 totally agree

4

Shows self-confidence, is able to assert himself/herself

totally disagree

disagree a little

neutral

2

agree a little

3

totally agree

\section{4}

Can be distant and cold towards others totally disagree

0 disagree a little

1 neutral

2 agree a little

3 totally agree

4
Perseveres until the task at hand is completed totally disagree

0 disagree a little

1 neutral

2 agree a little

3 totally agree

4

Can be moody

totally disagree

disagree a little

neutral

agree a little

3 totally agree

4

Is not really interested in different cultures, their customs and values

totally disagree

0

$$
\text { disagree a little }
$$

1 neutral

2 agree a little

3 totally agree

4

Is timid, shy

totally disagree

disagree a little

1 agree a little

3
4 neutral

2 totally agree

Is considerate and kind to almost everyone

totally disagree

disagree a little

neutral

2 agree a little

3 totally agree

4

Does things efficiently, works well and quickly

totally disagree

0 disagree a little

1 neutral

2 agree a little 3 totally agree 
Stays calm in tense or stressful situations

totally disagree

0 disagree a little

1 neutral

2 agree a little

3

totally agree

4

Likes to reflect, tries to understand complex things

totally disagree

disagree a little

neutral

2

agree a little

totally agree

$$
0
$$

1

2

3

4

Is extraverted, sociable

totally disagree

disagree a little

neutral

2

agree a little

3

totally agree

4

Can sometimes be rude or mean towards others

totally disagree

disagree a little

neutral

agree a little

3

totally agree

0

1

2

4

Plans things that need to be done and follows through the plans

totally disagree

0 disagree a little

1 neutral

2

totally agree

4

Can easily become nervous

totally disagree

0 disagree a little

1 neutral

2 agree a little

3

totally agree

4

Has few artistic interests

totally disagree

disagree a little

neutral

2

agree a little

3

totally agree

4

Likes exciting activities, which provide thrills

totally disagree

disagree a little

neutral

2

agree a little

3

totally agree

4

Likes to cooperate with others

totally disagree

0 disagree a little

1 neutral

2 agree a little

3 totally agree 
Is easily distracted, has difficulty remaining attentive

totally disagree

0 disagree a little

1 neutral

2

neutral

2 agree a little

3

agree a little

3

totally agree

4

totally agree

4

Is sophisticated when it comes to art, music or literature

totally disagree

0 disagree a little

1 neutral

2 agree a little

3 totally agree

4

Has a tendency to laugh and have fun easily

totally disagree

disagree a little

neutral

agree a little

2

3

totally agree

4
Can deceive and manipulate people to get what he/she want totally disagree

0 disagree a little

1 neutral

2 agree a little

3 totally agree

4

\section{Can do things impulsively without thinking about the consequences}

totally disagree

0 disagree a little

1 neutral

2

Has a tendency to be easily irritated

totally disagree

0 disagree a little

1 neutral

2 agree a little

3

agree a little

3 totally agree

4

totally agree 